\title{
Para una fenomenología de las muñecas hiperrealistas
}

\section{Towards a phenomenology of hyperrealistic dolls}

\author{
Pietro Conte \\ Ca' Foscari University of Venice, Italia
}

Resumen: Los artefactos hiperrealistas están extendiéndose de forma creciente y acelerada. "Muñecos reales [Real Dolls]" se usan como compañeros sexuales o de vida; "muñecos renacidos [Reborn Dolls]" reproducen de manera inquietante las características físicas de los niños reales; a corto plazo, es probable que los androides desempeñen un rol crucial prácticamente en todos los ámbitos de la sociedad; el rápido paso del desarrollo tecnológico sugiere ya que habrá un crecimiento exponencial en la aplicación de inteligencia artificial a las réplicas humanas. $\mathrm{Al}$ adoptar una perspectiva fenomenológica, este ensayo busca presentar una explicación teórica del hiperrealismo y de su traspasamiento de la línea entre "percepción" y "consciencia de imagen", entre "engaño" e "ilusión estética”, y entre arte y no arte.

Palabras clave: Estética fenomenológica, Hiperrealismo, Ilusión, Consciencia de imagen, marco.

Abstract: Hyper realistic artefacts are increasingly and rapidly spreading: "Real Dolls" are used as life- or sex partners; "Reborn Dolls" uncannily replicate the physical features of real infants; in the short term, androids are likely to play a crucial role in virtually all domains of society; and the rapid pace of technological development already suggests that there will be an exponential growth in the application of artificial intelligence to 
human replicas. By adopting a phenomenological perspective, this essay wants to provide a theoretical explanation of hyperrealism and its crossing the line between "perception" and "image consciousness", between "deception" and "aesthetic illusion", and between art and non-art.

Keywords: Phenomenological Aesthetics, Hyperrealism, Illusion, Image consciousness, Frame.

Recibido: 3 de septiembre de 2018

Aceptado: 8 de noviembre de 2018

\section{Observaciones preliminares}

" $A$ hora mismo vuelvo" (Be Right Back) es el primer episodio Ade la segunda temporada de la aclamada serie británica de ciencia ficción Black Mirror. Narra la historia de Martha, una joven cuyo novio, Ash, muere en un accidente de automóvil. En el funeral de Ash, Sara, amiga de Martha, le habla de un nuevo servicio tecnológico que permite a las personas comunicarse con un programa de inteligencia artificial que imita a los seres queridos que han muerto, mediante las redes sociales de las que eran usuarios, de sus contribuciones en línea y de los archivos personales de sus computadoras. A pesar de la renuencia inicial, Martha decide probar. Empieza a hablar con el Ash artificial casi sin parar, permitiéndose creer que en verdad está relacionándose con su compańero muerto. Al cabo de pocas semanas, el programa inteligente le informa acerca de la posibilidad de ser cargado en un cuerpo hecho de carne sintética. El resultado es un clon inesperadamente hiperrealista, que camina y habla y que es casi idéntico al verdadero Ash fallecido. Al igual que todos los episodios de la serie Black Mirror, "Ahora mismo vuelvo" está dedicado a imaginar las consecuencias posibles del uso de nuevas tecnologías en un futuro próximo. A pesar de ser una historia de ciencia ficción, está inspirada en el desarrollo técnico y tecnológico de punta que 
existe actualmente. El sueño (o más bien la pesadilla) de que los clones artificiales puedan actuar como sustitutos de personas reales se vuelve efectivamente más y más real gracias al uso de ciertos materiales - de la cera tradicional a las más sofisticadas resinas de silicón y poliéster- que hacen posible construir réplicas visualmente perfectas de seres humanos.

Un caso revelador es el de los muñecos hiperrealistas que copian a sus modelos en persona y parecen (casi) indiscernibles de sus homólogos reales. Desde los llamados "muñecos reales" (Real Dolls), cuya función principal es servir como pareja sexual, a los más escalofriantes "muñecos renacidos" (Reborn Dolls) -muñecos industriales de piel, desensamblados y transformados para recrear perfectamente la apariencia, textura y peso de los niños reales-, todos estos artefactos están diseñados para empañar drásticamente el umbral que separa la realidad del mundo-de-la-vida de la (ir) realidad del mundo-de-la-imagen. Los creadores de tales muñecos hiperrealistas afirman además ser artistas, y no meros productores. "Real Doll" (Muñeco real) es también el nombre de la compañía fundada en 1997 por Matt McMullen, quien había sido escultor; por su parte, una asociación "International Reborn Doll Artists (IRDA)" (Artistas internacionales de muñecos renacidos) se fundó en 2005. Pero, ¿pueden considerarse esos costosos muñecos auténticas obras de arte? Puede encontrarse respuesta a esta pregunta sólo si se ofrece una explicación teórica de qué significa el hiperrealismo, y si, en principio, éste puede acceder al ámbito del "gran arte". Para proporcionar tal explicación, quisiera empezar con algunos ejemplos paradigmáticos.

2. Damas y guardias: imágenes que niegan sí mismas

Ferdinand-Sigismond Bac fue el sobrino ilegítimo de Jérôme Bonaparte, el hermano menor de Napoleón. Criado en Austria en el 
margen de la corte del Segundo Imperio Francés, decidió mudarse a París después del colapso del régimen. Ahí, el prince impérial, Napoleón Eugène Louis Bonaparte (Napoleón IV para los Bonapartistas) lo introdujo en la alta Sociedad, permitiéndole llevar una vida acomodada y perfectamente bohemia. Escritor, pintor, ilustrador, diseñador de jardines y uno de los destacados caricaturistas de su tiempo, el joven Ferdinand amplió su círculo social hasta incluir en él celebridades como Víctor Hugo, Paul Verlaine, Guy de Maupassant, Giuseppe Verdi y Richard Wagner, por mencionar algunos.

Entre los muchos eventos emocionantes en la biografía de Bac, el que quisiera enfatizar aquí podría parecer a primera vista de menor si no es que de marginal importancia. Se encuentra oculto entre las fascinantes páginas de su Viaje a Berlin. Después de un largo paseo a orillas del río Speer, Bac llega al Palais Monbijou, residencia del antiguo museo Hohenzollern. ${ }^{1}$ Intrigado, entra a visitar las cuarenta y dos habitaciones que alojan las colecciones de la Cámara de Arte Real (Königliche Kunstkammer), que con el tiempo habían sido enriquecidas con una serie de artefactos que celebraban la gloriosa historia de la residencia. De pronto, se encuentra con "una misteriosa figura que, sentada en un sillón al lado de una puerta, parece ser parte del personal de vigilancia. Su mirada somnolienta es característica de los guardias de museo, con los ojos a punto de cerrarse en cualquier momento". Vestido con ropa pasada de moda, con un sombrero de ala ancha en la cabeza y una bata de armiño sobre los hombros, "permanece ahí, observando en silencio a los visitantes". Impresionado, pero sin saber realmente por qué, Bac se aleja del guardia para verlo mejor $y$, finalmente, resuelve el misterio. “¿Quién es este extraño hombre que supervisa

${ }^{1}$ Lo que quedó del museo, severamente dañado por los bombardeos durante la Segunda Guerra Mundial, fue demolido en 1959. 
el salón? Es un muñeco de cera, un impresionante trompe l'œeil que se parece a Federico I de Prusia" (Bach, 1929: 51).

Con extraordinaria capacidad mimética, el maniquí hiperrealista fue hecho para engañar al observador y para encubrir su verdadera naturaleza, ocultando el hecho de que "no es más que una imagen”. Busca salir del marco de representación y entrar en nuestro mundo, el mundo de la realidad de carne y hueso. Para lograrlo, debe desdibujar los límites entre las dos esferas tanto como sea posible, tratando de deshacerse de cualquier elemento que pueda desenmascararlo como mera "representación". En el relato de Bac, lo que traiciona al "guardián" es la vestimenta anacrónica, que levanta la sospecha de que algo no encaja, y lleva al visitante a alejarse y ver de nuevo. Este distanciamiento restablece, desde un punto de vista meramente físico, la brecha entre el mundo de la imagen del mundo de la vida, brecha que la figura de cera, en cambio, quiere salvar. Es precisamente gracias a esta distancia que lo que antes había parecido un guardia anónimo resulta ser una representación hiperrealista de una "celebridad" que, en la época del relato de Bac, claramente ya no era famosa.

Este punto no debería ser pasado por alto. Encontrarse con celebridades es muy poco común. Los poderosos, los ricos y los famosos suelen estar rodeados de un aura particular que parece hacerlos excepcionalmente lejanos, incluso en las pocas ocasiones en que uno podría estar físicamente cerca de ellos. Son iconos, imágenes inalcanzables de sí mismos. Su naturaleza intrínsecamente icónica es lo que los hace inmediatamente reconocibles y evita que pasen desapercibidos; para las celebridades es casi imposible introducirse en la multitud y mezclarse con gente "común". Su reiterado reclamo de privacidad no implica un deseo de aislamiento, sino todo lo contrario: es el deseo de actuar y sentir "como todo el mundo", al menos por un momento. 
La visita de Bac al museo Hohenzollern se remonta a 1929. Más de dos siglos habían pasado desde la muerte de Federico I en 1713; por ello, es perfectamente comprensible que el intelectual francés no haya reconocido de inmediato al monarca. Pero es precisamente este anonimato lo que facilita la tarea de la escultura de cera, dejándole -aunque sea por un momento- pasar inadvertida e incorporarse a los guardias vivos, como una persona entre la gente. Sin marco que lo aísle de la realidad ordinaria y lo declare un artefacto, el maniquí es un extraño en el mundo al que sin embargo pertenece -el mundo de la representación-.

Si decidimos pasar algunas horas en el Madame Tussauds, sabemos exactamente qué esperar. Como todos los museos, los de cera son también parte de los llamados "marcos institucionales": ambientes que generan expectativas particulares. Al entrar en un museo o galería de arte, uno siempre cruza un umbral, una línea que separa la realidad ordinaria de la "irrealidad" de la experiencia icónica: "La galería ideal sustrae del objeto artístico todo indicio que pueda interferir con el hecho de que se trata de 'arte'. La obra se encuentra aislada de todo aquello que pueda menoscabar su propia autoevaluación" (O’Doherty, 1999: 20). Aislamiento es una función característica de todo marco; por el simple hecho de estar ubicado dentro del marco de un museo, un objeto adquiere un valor particular, un estatus icónico que lo distingue de todas las cosas ordinarias.

Esto mismo pasa en museos como el Madame Tussauds o el Grévin, que no pretenden pertenecer al mundo del arte. Como todos los marcos, también generan expectativas; esperamos encontrar ahí, si no obras de arte, al menos imágenes, esto es, representaciones que, como tales, deben revelar su carácter icónico más allá -y a pesar- de su deslumbrante realismo. Para que esto suceda, no obstante, la imagen debe dar-se claramente como imagen; el hecho de que se encuentre enmarcada por el museo ayuda a alcanzar pre- 
cisamente este objetivo. "La estabilidad del marco resulta tan necesaria como la botella de oxígeno para un buceador. La seguridad con que se trazan sus límites define por completo la experiencia que sucede en su interior" (O’Doherty, 1999: 24).

Sin embargo, el espacio del museo no coincide completamente con el espacio de la representación. El vestíbulo, la taquilla, la cafetería, la tienda de libros o los sanitarios son ambientes que pertenecen a la realidad común y que normalmente nada tienen que ver con la "irrealidad" (Fink, 1930) del mundo de la representación. Los museos son grandes marcos que, como las cajas chinas, incluyen marcos progresivamente menores que delimitan cada vez más el espacio representacional en el que se enfoca la mirada del observador. Las salas en una galería de arte y, dentro de ellas, los espacios específicamente diseñados para exhibir las obras de arte individuales, gracias a su aislamiento de la realidad ordinaria por medio de barreras o líneas divisorias de diversos tipos, sirven como marco para guiar al visitante y ofrecerle una suerte de mapa cuyos límites entre la realidad y la representación están cada vez más claramente señalados. Eso es lo que son los marcos: herramientas de orientación. Mientras más fuerte es la delimitación establecida por el marco, más fácil será orientar la mirada del observador. Lo mismo a la inversa: mientras más poroso y matizado sea el marco, más confundido y desorientado estará el observador. De modo que un objeto ordinario -como enseña Duchamp- adquiere un valor extra-ordinario tan pronto como se le aísla dentro de un marco. Pero ¿qué pasa cuando un objeto enmarcado (y por lo tanto separado de la realidad ordinaria) es privado de su "aislador" -como Ortega y Gasset (1921: 311) definía al marco del cuadro- y arrojado al continuidad espaciotemporal de la realidad ordinaria?

En 1928, un año antes de que Ferdinand Bac visitara el museo Hohenzollern, uno de los grandes intelectuales del siglo xx había encontrado, sin proponérselo, la respuesta a esta pregunta. En una 
de las famosas páginas de su novela autobiográfica Nadja, André Breton describe su experiencia en el museo Grévin. Llega, paga su boleto e inicia la visita. De pronto, "cuando se pasa de la sala de las celebridades políticas modernas a la sala en cuyo fondo, detrás de una cortina, se representa una 'velada en el teatro'", repara en una mujer que se aparta en la sombra para arreglar su liguero. La tentación es irresistible; después de asegurarse rápidamente que nadie está viendo, Breton se entrega al instinto voyerista y lanza una mirada fugaz hacia la intrigante escena. Nada ha cambiado, todo permanece exactamente como antes -exactamente como antes-. Tan innatural quietud contradice sus expectativas y le pide que vuelva a mirar; el mismo resultado, ningún movimiento, ningún cambio. Ninguna vida. La mujer del liguero no es sino un "adorable señuelo" hecho precisamente para engañar a los visitantes; es "la única estatua" -como Breton con admiración lo dice- "que tiene ojos, los ojos de la provocación” (Breton, 1928: 126-127).

Es muy significativo que tanto Bac como Breton le atribuyan mirada a los maniquíes hiperrealistas que los engañaron. El dicho "los ojos son el espejo del alma" no es una coincidencia; la mirada está fuertemente ligada al mundo de la vida. Al referirse a la experiencia de Breton, Walter Benjamin (1927-1940: 97) afirmó que es imposible no enamorarse perdidamente de la perturbadora "eternización de lo efímero [Verewigung des Ephemeren]" representada por la dama de cera. Lo "efímero" es el signo mismo de la vida, inevitablemente sujeta al cambio incesante. La "mujer" anónima abrochándose el liguero es en efecto atrapada en un momento que debería ser privado, ajeno a los ojos que espían. A diferencia de las figuras de cera comunes, ella no es exhibida ni está expuesta: no está ubicada dentro de una sala sino entre dos habitaciones, en un lugar de tránsito que no está sujeto a las leyes de la representación sino a las del mundo real, el mundo de la percepción. Como señala Hans Blumenberg, "las figuras de cera no tienen por finalidad 
ser miradas como meras imágenes sino como personas de carne" (1989: 714).

Una experiencia conceptualmente idéntica a las descritas por Bac, Breton y Benjamin fue registrada -antes que por ellos- por Konrad Lange:

Recuerdo que hace unos años, en la cima de la escalera del Panóptico de Castan en Berlín, había una dama de cera con la cabeza inclinada que se llevaba los impertinentes (lorgnette) a los ojos de vez en cuanto, haciendo un guiño a los visitantes que subían. Los que la veían por primera vez eran casi siempre engañados; luego, al acercarse y observar mejor sus movimientos, se daban cuenta de que habían caído en la trampa. En tales casos, desde luego, el goce estético sale por la ventana. [...] El goce estético genuino sólo se encuentra cuando el artista renuncia a toda forma de engaño real [wirkliche Täuschung] desde el comienzo, garantizando suficientes momentos anti-ilusionistas para crear en el observador una ilusión consciente [bewusste Selbsttäuschung]. Cuando el espectador considera la obra de arte como una pura y simple apariencia estética y se deja llevar más y más por la ilusión, casi hasta el punto de confundir la imagen con la realidad, entonces surge la ilusión consciente y, con ella, el goce estético. Por otro lado, cuando el espectador es engañado al principio, y luego descubre que ha caído en la trampa, lo que surge no es otra cosa que desilusión [Enttäuschung], es decir, un sentimiento de displacer (1901: I, 245-246).

El engaño real -es decir, la ilusión perceptiva- necesariamente lleva a la desilusión y, por consiguiente, a la decepción; la ilusión consciente (es decir, la ilusión estética), en cambio, conduce a un juego de analogías en el que la imagen es reconocida como tal desde el principio. Desprovista de cualquier tipo de marco que denuncie su condición de artefacto, la estatua de cera escapa del espacio de la representación y entra al espacio de la realidad de carne y hueso, generando así en el observador una serie de expectativas de percep- 
ción que, no obstante, permanecerán inevitablemente sin correspondencia: la rigidez de los movimientos de la mujer, su mirada fija, el tono ligeramente antinatural de su piel, revelan finalmente que es en realidad la imagen de una persona.

Curiosamente, la misma anécdota que Lange menciona aparece, descrita en términos sorprendentemente similares, también en Husserl: "Recuerdo la escena de las piezas de cera en Berlín: Cómo me sobrecogí cuando la demasiado amable 'dama' de la escalera me hizo señas para que me acercara. Y cómo, después de recuperar la compostura, advertí de pronto que era un maniquí hecho para engañarme" (1912a: 497). Estas líneas fueron escritas en 1912, pero la visita a Castan se remonta al tiempo en que el padre de la fenomenología era un joven estudiante de matemáticas. El relato, que se repite como un auténtico leitmotiv en el corpus husserliano, había ya encontrado un lugar en las Investigaciones Lógicas, publicadas entre 1900 y 1901. "Paseando por el poliorama encontramos en la escalera a una bella desconocida, la consabida sorpresa del poliorama. Es una muñeca, que nos ha engañado por un momento. Mientras somos presa de la ilusión, tenemos una percepción, tan percepción como otra cualquiera. Vemos una dama, no una muñeca. Reconocido el engaño, sucede a la inversa; vemos una muñeca, que representa a una dama” (Husserl, 1900-1901: II, 543). Tanto en Lange como en Husserl, la conciencia del observador frente a algo que no es sino una imagen es la conditio sine qua non de la representación. A su vez, esta conciencia se basa en el reconocimiento de ciertos elementos de diferencia y contraste entre la imagen y su referente. Sin dicho contraste, el juego de la representación se pierde y la ilusión estética da paso a la ilusión perceptual.

Pero lo que el guardia de cera y la dama de cera son es precisamente esto: imágenes que hacen todo lo posible por no ser reconocidas como tales; imágenes que tratan, por todos los medios, de negar sí mismas (Vid. Conte (2014); Pinotti, (2017). Las 
imágenes hiperrealistas buscan oscurecer la diferencia entre la cosa física y el objeto icónico. Al ver un retrato pintado de un hombre, normalmente no hay dificultad en distinguir entre el médium y la imagen; por un lado, hay un lienzo cubierto con pigmentos, por el otro, un rostro. Incluso cuando se ve una fotografía, la reproducción mimética par excellence, las mínimas diferencias entre la cosa física y el objeto icónico son demasiado evidentes: los matices cromáticos, la forma y dimensión del papel fotográfico no son, desde luego, los del objeto que aparece en el papel. Pero se podría tal vez objetar que estos son ejemplos demasiado simples y no representativos, dado que los cuadros y las fotografías son objetos bidimensionales, mientras que los objetos icónicos que aparecen en ellos remiten a sujetos tridimensionales. En principio, no obstante, algo así podría decirse de las bustos esculpidos en tamaño natural, que pueden ser inmediatamente reconocidos como imágenes, y que sólo como tales tienen posibilidad de merecer su lugar en las galerías de arte. Pero en el caso de las figuras de cera todo es mucho más complicado. ¿Dónde termina la cera, y dónde empieza la carne representada? ¿Dónde termina la cosa física y dónde empieza el objeto icónico? Lo primero es tan semejante a lo segundo que tiende a identificarse con él. En este sentido, entonces, lo que es negado es un rasgo fundamental de la conciencia pictórica; el "conflicto" o diferencia entre la cosa física y el objeto icónico se ha perdido, lo cual significa que ya no es posible afirmar que una imagen aparece por medio de una cosa, pues la imagen y la cosa ahora se pueden superponer una a la otra.

Sin embargo, la dama y el guardia no eliminan solamente la diferencia entre la cosa física y el objeto icónico; también buscan aniquilar la diferencia entre el objeto icónico y el sujeto icónico. Su poder mimético es demasiado fuerte, demasiado inmediato, en el sentido literal del término -hace que la mediatez imprescindible de la representación se esfume-. Pero el que no haya mediatez 
implica que no hay imagen. Cuando reflexiona sobre los límites de la representación, Husserl menciona el "caso límite", en el cual la aprehensión directa del objeto icónico coincide con la aprehensión indirecta del sujeto icónico, de manera tan perfecta que se vuelven indiscernibles: "En el caso de un retrato perfecto que presenta perfectamente a la persona con todos sus detalles (todo lo que pueden ser sus rasgos característicos), en efecto, incluso en un retrato que logra esto del modo menos satisfactorio, sentimos como si la persona misma estuviera ahí". Pero sólo "como si”, pues normalmente la "persona misma" pertenece a un contexto distinto al del objeto icónico. "La persona real se mueve, habla y demás; la persona imagen es una figura estática, muda” (1904-1905: 33-34).

Éste es generalmente el caso. Pero las figuras hiperrealistas, como las estatuas del Madame Tussauds o los muñecos "reales" y "renacidos", cambian todo el juego, pues tienen -aún si sólo por un momento- la misma fuerza, la misma estabilidad, la misma plenitud que les atribuimos a los objetos percibidos. Gracias a dispositivos mecánicos, pueden incluso moverse y decir palabras, encarnando perfectamente el "caso límite", en el que la síntesis entre objeto icónico y sujeto icónico abarca todos los detalles de la apariencia del primero que pueden parecerse a las cualidades inferidas en la aprehensión del segundo. Al estar ausente el mínimo grado de diferencia que se requiere para distinguir entre la imagen que representa y el objeto representado, la semejanza se convierte en indiscernibilidad. En este segundo sentido, la "dama" niega entonces otra condición esencial de la conciencia pictórica, la del "objeto doble"; esto es, el objeto icónico y el sujeto icónico se vuelven indiscernibles entre ellos.

Las figuras de cera y los muńecos hiperrealistas no son estructuras referenciales; están hechos para presentar, más que para representar algo o a alguien. Y esto es por lo que, mientras tomemos un muñeco por una persona real, tendremos una percepción normal. 
La dama aparece encarnada y es confundida con una persona real. A diferencia de la imagen propiamente dicha, su espacio es nuestro espacio, su tiempo el nuestro. "Ella" respira el aire que nosotros respiramos; "ella" existe en nuestro mismo ambiente. "Ella" nos devuelve la mirada. Una muñeca de cera es la aparición de una persona real.

La conciencia de la realidad puede ser inhibida por entrar en conflicto con otra conciencia de realidad, pero es conciencia de la realidad. El objeto ilusorio [Scheinding] se encuentra frente a mí en la unión de estas cosas físicas que pertenecen a mi entorno, en el mismo espacio, como una cosa entre ellas y tan real como ellas. La figura de cera tiene cabello real, ropa real. Todo -o casi todo- lo que le pertenece y que genuinamente aparece, aparece con tanta realidad como lo hacen otras cosas. Sólo cuando la examino detenidamente emergen las diferencias, las vacilaciones y demás. En el caso de la imagen normal, pero desde luego también en el de un objeto-imagen claramente diferenciado del tema de la imagen, no tengo conciencia alguna de la realidad, ni siquiera una conciencia 'inhibida'. No tengo inclinación alguna a tomar por real el objetoimagen (Husserl, 1912b: 480).

Pero, ¡cómo es entonces que el muñeco hiperrealista es finalmente reconocido como imagen y no como persona? ¿Cómo nos damos cuenta de que hemos sido engañados? Para que esto suceda, debe empezar a debilitarse el "horizonte de familiaridades" (Husserl, 1948: 53, 55) en que los objetos ordinarios son percibidos. Las cosas deben dejar de tener sentido, algunos elementos deben provocar sospecha, llevándonos a verificar dos veces para dejar las cosas claras. En cuanto a las figuras de cera, el elemento de sospecha generalmente consiste en la falta de movimiento o -si la estatua está equipada con dispositivos que le permitan hacer gestos relativamente complejosen lo mecánico de sus movimientos. Podemos imaginar fácilmente la escena: Husserl entra al museo y se dirige a la taquilla. Se forma en 
la fila, echa un distraído vistazo a la escalera y ve a una dama indicándole que suba. Desconcertado, mira a su alrededor para cerciorarse de que él es el invitado y, al no ver a nadie cerca, voltea de nuevo hacia la dama. Una vez más, encuentra los mismos, idénticos gestos: la cabeza se levanta y gira ligeramente, el pecho y el brazo se mueven como corresponde. Déjà vu.

Aquí es cuando la ilusión perceptiva empieza a vacilar o, más bien, aquí es cuando desaparece. Porque la ilusión perceptiva implica siempre una creencia total; no permite dudas, ni siquiera la menor suspensión del juicio. A diferencia de la aparición de la imagen, que claramente se presenta como una imagen, la emergencia de la ilusión perceptiva permanece escondida -no quiere ser notada-. Cuando es reconocida, el juego se termina; se ha terminado desde hace un tiempo, es decir, desde que uno empezó a dudar de su verdadera naturaleza:

El que uno sea víctima de la ilusión es algo que no se entiende mientras se esté atrapado en la ilusión misma. La conciencia de la imagen, en cambio, es siempre conciencia de la imagen qua imagen. En un sentido estricto, la apariencia de ilusión es siempre una apariencia pasada ('Había caído en una ilusión'), mientras que la apariencia de la imagen es una apariencia presente ('Estoy contemplando una imagen ahora mismo') (Seemann, 2000: 128129).

Como Jean Baudrillard sostiene, "mientras una ilusión no es reconocida como un error, su valor es exactamente equivalente al de una realidad. Pero una vez reconocida la ilusión como tal, deja de serlo. Es, pues, el concepto de ilusión, y sólo él, lo que es una ilusión" (1995: 76).

Los muñecos hiperrealistas fascinan a los fenomenólogos precisamente porque les permiten investigar la relación entre imagen e ilusión, así como la relación entre conciencia pictórica y con- 
ciencia perceptiva. El presente de la percepción está entrelazado con retenciones relacionadas con la experiencia pasada y con protenciones que anticipan su curso futuro. La sorpresa y la desorientación siempre provienen de expectativas no cumplidas, pues nuestra creencia en un mundo que existe en sí mismo está basada precisamente en estas expectativas y en su cumplimiento. La dama de Husserl desafía la coherencia de la experiencia: "La creencia perceptiva pierde por un momento su carácter de creencia porque se remonta a una percepción engañosa y compite con otra creencia" (Därmann, 1995: 284). Primero era una mujer; ahora es un maniquí. ¿Terminó el juego? Bueno, las cosas no son tan sencillas. La dama y el guardia todavía tienen un as bajo la manga y no dejarán de usarlo. Aun cuando han sido desenmascarados, no se rinden; todavía quieren ganar. Y ganan, efectivamente: "Con su genuina ropa, cabello y demás, en efecto, incluso con movimientos imitados artificialmente por medio de aparatos mecánicos, la figura de cera se parece tanto al ser humano natural, que la conciencia perceptiva momentáneamente se impone una y otra vez. La aprehensión imaginativa es suprimida" (Husserl, 1904-1905: 43).

Desde una perspectiva fenomenológica, se trata de una afirmación verdaderamente decisiva, pues implica que el problema en cuestión no puede ser resuelto recurriendo a consideraciones puramente ontológicas: nada distingue al maniquí del ser humano real, salvo un acto diferente de la conciencia intencional. Incluso éste, no obstante, lucha frente a la figura de cera, oscilando indefinidamente entre la aprehensión perceptiva y la aprehensión pictórica, quedando por lo tanto atrapado en "un tipo de 'parálisis" (Steinmetz, 2011: 135). La semejanza excesiva oscurece el carácter "irreal" de la imagen y provoca que la tensión entre presencia y ausencia inherente al concepto de "representación" fracase, lo que acaba en que, aun cuando nos damos cuenta de que estamos frente a la imagen de una persona, no podemos sino ver a la persona mis- 
ma de carne, y no de cera. La conciencia pictórica, después de haber derrocado temporalmente a la conciencia perceptiva, no tiene ya más trato con ella; busca una y otra vez imponerse y recordarnos que somos en realidad las víctimas de una ilusión: cera, no carne.

El tiempo, como se sabe, siempre aclara las cosas. Unos cuantos momentos suelen ser suficientes para darnos cuenta de que hemos caído en la trampa del maniquí. Pero aun así, "no podemos evitarlo -vemos un ser humano" (Husserl, 1904-1905: 43-44). Este es el dato fenomenológico más relevante: el desequilibrio en marcha entre saber y ver. La conciencia perceptiva no puede tomar completamente el control debido a la duda que lentamente se arrastra, afectando el curso normal de la percepción; sin embargo, la conciencia pictórica también fracasa en tener el control porque la semejanza extraordinaria entre la figura de cera y la persona real siempre nos compromete a retroceder de nuevo desde la aprehensión pictórica a la aprehensión perceptiva.

\section{Muñecos hiperrealistas: ¿arte o no arte?}

Es debido a la "indecisión de confines entre lo artístico y lo vital" (Ortega y Gasset, 1921: 311) que los muńecos de cera no pertenecen a la esfera del arte. Como Lange, Husserl también nota que basta con que el observador sea momentáneamente engańado por las figuras de cera para impedirle experimentar un auténtico goce estético.

La imagen debe estar claramente separada de la realidad; esto es, separada de un modo puramente intuitivo, sin asistencia alguna de pensamientos indirectos. Deberíamos ser sacados de la realidad empírica y elevados a un mundo de imaginería igualmente intuitivo. La apariencia estética [Schein] no es ilusión sensorial [Sinnentrug]. El deleite en la decepción directa o en el crudo conflicto entre la realidad y la apariencia, en el que ya la apariencia 
pasa como realidad, ya la realidad como apariencia -realidad y apariencia jugando a las escondidas, por decirlo así- es la antítesis extrema del placer estético, fundado en la serena y clara conciencia de imagen. Los efectos estéticos no son los efectos de las ferias anuales (Husserl, 1904-1905: 44).

No importa si son damas o guardias, las imágenes hiperrealistas están, en todo caso y en principio, fuera de marco; su objetivo es, en efecto, no ser imágenes "enmarcadas". El situarlas fuera del espacio ordinario de la exhibición no hace sino volverlas más transgresivas, acentuando su capacidad de transgredi, ${ }^{2}$ de "pasarse de la raya", de atravesar el umbral de la representación y volverse parte de nuestro mundo. Es precisamente esta característica lo que las hace, tanto en Lange como en Husserl, intrínsecamente no estéticas; las figuras de cera, los "muñecos reales" y similares no pueden ser considerados, en principio, como una forma genuina de arte.

Pero, como sabemos, cuando se trata de arte -particularmente de arte contemporáneo- la sorpresa aguarda siempre a la vuelta de la esquina. Y la esquina, en este caso, se encuentra detrás de la entrada de una de las salas del Museo de Arte Nelson-Atkins en Kansas City, Missouri. ¿Quién es el guardia que mira con tristeza fuera de la ventana, absorto en sus pensamientos? Es el Guardia del Museo, alias Roy, como lo llaman los demás guardias; una figura hiperrealista creada por Duane Hanson en 1975. De modo que es una obra de arte. Una estatua que, igual que los guardias falsos y las damas falsas sobre los que hemos discutido antes, parece hecho para engańar al viandante. Él también depende del extraordinario grado de realismo garantizado por el uso de poliéster, fibra de vidrio y vinilo, los herederos modernos de la cera; él también está cuidadosamente ubicado fuera de los espacios tradicionales de exhibición, en lugares donde los visitantes pueden aproximársele sin restricción alguna.

${ }^{2}$ En latín, pasar a través de [N. T.] 
Entre 2011 y 2012, en ocasión de una retrospectiva dedicada a George Ault, el guardia de Hanson fue trasladado a una sala que no es en la que usualmente se le puede encontrar (o mejor dicho, en la que uno puede "encontrarse con él"); los curadores del museo dejaron a Roy explicar "él mismo" las razones de este cambio temporal. Un letrero al lado de la entrada a la sala decía lo siguiente:

La escultura realista de Duane Hanson, Guardia del Museo, se ha mantenido fielmente en su puesto en la galería L3 desde que el Edificio Bloch se inauguró en 2007. Ahora que las dos galerías de arte contemporáneo han sido desocupadas para dar lugar a la exposición Hacer un Mundo: George Ault y Estados Unidos en los años 1940, Roy pidió ser asignado a otro lugar en el museo. "Desde mi llegada al Nelson-Atkins el 18 de Noviembre de 1976, no he escuchado más que elogios al museo. Ahora tengo la fortuna de ver aquello de lo que todos han estado hablando. Por los próximos dos meses, estaré en este hermoso hogar histórico de los Estados Unidos", dijo. "Entonces, seré reasignado a la galería P24, donde conoceré la elegancia de la vida inglesa del siglo XviII, en la Sala King's Lynn".

Este letrero puede ayudar a entender la diferencia entre Roy y los falsos guardias de museos. El tono claramente irónico del mensaje no aumenta sino disminuye drásticamente el "efecto de realidad" de la imagen; de ese modo, hace explícita la naturaleza traviesa de la instalación: los curadores invitan a los visitantes a jugar el juego de Roy. Lo más importante, no obstante, es que es un juego desde el principio, es decir, desde el momento mismo en que uno entra al Museo Nelson-Atkins. La obra de Duane Hanson es parte de la colección de una institución que, a diferencia de Madame Tussauds, es un museo de arte y, como tal, genera expectativas diferentes a las de un museo de cera. La diferencia radica en el marco en el que la obra se inserta. Desde luego, un visitante podría simplemente no saber que Roy es una obra de arte, con lo cual sería más probable 
que cayera en la trampa puesta por el "guardia". Sin embargo, aun en este caso, hay otro marco provisto para restablecer la distancia correcta entre la imagen y la realidad: el rótulo que ofrece información sobre la obra también contribuye a delimitar el campo de la ilusión estética como opuesto al del verdadero engaño.

Como Gombrich advirtió, en realidad, las muñecas de cera "de las galerías, con rótulos, son 'retratos de los grandes'. La figura que hay al pie de la escalera, hecha para engañar al visitante, representa a 'un' empleado, un miembro de una clase. Está ahí como 'sustitutivo' del vigilante que esperaríamos" (1951: 3). Pero el guardia del Nelson-Atkins ya no es "un" guardia; es "el" guardia de Duane Hanson, es Roy -un hombre ordinario convertido en celebridad-. El guardia falso de los museos de cera convencionales -como el que menciona Rudolf Arnheim- no está hecho para "interpretar la naturaleza de sus colegas guardias, sino para aumentar el personal de la institución de manera extraña" (1959: 72). Al delatarse como obra de arte, en cambio, Roy nos invita a reflexionar precisamente en la "naturaleza" del guardia, en su condición existencial, en su humanidad - un tema central en toda la producción de Duane Hanson-. Podría decirse, por lo tanto, que entre los muchos significados que uno podría dar a Guardia de Museo, se encuentra el de una problematización irónica, pero seria, de la relación entre el hiperrealismo à la Madame Tussauds, "muñecos reales" o "muñecos renacidos", que sólo se logra escapando al marco de la representación, y un hiperrealismo que consigue elevarse por encima del simple virtuosismo técnico y la imitación por su propio beneficio, expandiendo los marcos del arte en nuevas e inesperadas direcciones. 


\section{Bibliografía}

Arnheim, Rudolf, 1959, "The Robin and the Saint: On the Twofold Nature of the Artistic Image", The Journal of Aesthetics and Art Criticism, vol. 18, núm. 1, pp. 68-79.

Bac, Ferdinand-Sigismond, 1929, Le voyage à Berlin. La fin de l'Allemagne romantique, Conard, París.

Baudrillard, Jean, 1995, El crimen perfecto, 1996, Joaquín Jordá (trad.), Anagrama, Barcelona.

Benjamin, Walter, 1927-1940, Libro de los Pasajes, 2004, Rolf Tiedemann (ed.), Luis Fernández Castañeda, Isidro Herrera y Fernando Guerrero (trad.), Akal, Madrid.

Blumenberg, Hans, 1989, Höblenausgänge, Suhrkamp, Frankfurt am Main.

Breton, André, 1928, Nadja, 2004, José Ignacio Velazquez (trad.), Cátedra, Madrid.

Conte, Pietro, 2014, In carne e cera. Estetica e fenomenologia delliperrealismo, Quodlibet, Macerata.

Pinotti, Andrea, 2017, "Self-Negating Images: Towards An-Iconology", Proceedings, vol. 1, pp. 1-9.

Därmann, Iris, 1995, Tod und Bild. Eine phänomenologische Mediengeschichte, Fink, Munich.

Fink, Eugen, 1930, "Vergegenwärtigung und Bild. Beiträge zur Phänomenologie der Unwirklichkeit", Jahrbuch für Philosophie und phänomenologische Forschung, vol. 11, pp. 239-309.

Gombrich, Ernst, 1951, "Meditaciones sobre un caballo de juguete o Las raíces de la forma artística", en Meditaciones sobre un caballo de juguete y otros ensayos sobre la teoría del arte, 1996, José María Valverde (trad.), Debate, Madrid, pp. 3-11. 
Husserl, Edmund, 1900-1902, Investigaciones Lógicas, 2005, Manuel García Morente y José Gaos (trad.), 2 vol., Alianza, Buenos Aires.

, 1904-1905, "Phantasy and Image Consciousness", en Husserl, 2005, pp. 1-115.

, 1912a, "On the Analysis of Memory. Characterization of Internal Memory and Characterization through the Later Nexus. Omission and Supervention of Position Takings" (1912), en Husserl, 2005, pp. 497-507.

, 1912b, "Reproduction and Image Consciousness", Appendix L: "On Imagination" (1912), en Husserl, 2005, pp. 569-573.

, 1948, Experiencia y Juicio. Investigaciones acerca de la genealogía de la lógica, 1980, Jas Reuter (trad.), Bernabé Navarro (revisión), Ludwig Landgrebe (ed.), Lothar Eley (epílogo), Instituto de Investigaciones Filosóficas, unam, México.

, 2005, Phantasy, Image Consciousness, and Memory (18981925), John B. Brough (trad), Springer, Dordrecht.

Lange, Konrad, 1901, Das Wesen der Kunst: Grundzüge einer realistischen Kunstlehre, 2 vols, Grote'sche Verlagsbuchhandlung, Berlín.

O’Doherty, Brian, 1999, Dentro del cubo blanco. La ideología del espacio expositivo, 2011, Lena Peńate Spicer (trad.) Fernando Villaverde y Marta Morales (revisión), Centro de Documentación y Estudios Avanzados de Arte Contemporáneo, Murcia.

Ortega y Gasset, José, 1921, "Meditación del marco", en Obras completas de José Ortega y Gasset, tomo 2, 1963, Revista de Occidente, Madrid, pp.307-313.

Seemann, Hans Jürgen, 2000, Bild als Widerstreit. Zur Phänomenologie des Bildes im Anschluß an die Untersuchungen E. Husserls. 
Ein Beitrag zur Phänomenologie der anschaulichen Unmöglichkeit, Dissertation, Wuppertal.

Steinmetz, Rudy, 2011, L'esthétique phénoménologique de Husserl. Une approche contrastée, Kimé, París. 